\title{
EDITORIAL
}

\section{CSRD has become SICS}

\author{
Sabine Glesner ${ }^{1}$
}

(c) Springer-Verlag GmbH Germany, part of Springer Nature 2019

Modern societies have undergone major changes during the last decade. Especially information and communication technologies have increasingly shaped many facets of the daily lives of many human beings as well as of, for example, industrial production, medicine technology, logistics, traffic management, environmental technology, and agriculture. Cyber-physical systems play a major role in this development. In many cases, they are equipped with large amounts of software and pose radically new challenges to developers and also users of these systems. This journal takes these developments into account and, hence, puts a special focus on software-intensive cyber-physical systems.

Cyber-physical systems in general are distributed systems consisting of embedded subsystems that are connected by a network, in many cases by the internet itself as well as by local and/or proprietary networks. The range of cyberphysical systems is broad, spanning from cars and planes to smart homes and smart cities to energy management systems and globally spread production networks. Often, these systems are labelled smart or intelligent, which in most of the cases means that software is used to enhance and augment their functionality.

With the new journal Software-Intensive Cyber-Physical Systems (SICS), we want to put a special focus on these newly emerged systems and create a scientific and innovation oriented space to present cutting-edge research and developments in this area, always with a particular attention to the software-side of the systems.

This journal, even though just newly founded, has already a long tradition in software engineering research as it is the successor of the well-known journal Computer ScienceResearch and Development (CSRD), which itself is the successor of the formerly German-based journal InformatikForschung und Entwicklung (IFE). Even though the title of CSRD has been rather universal, the journal has always paid special attention to software engineering research and developments, always also seeking to attract industrial papers as well as, of course, papers from the academic domain. We hope to continue our tradition of publishing research papers of high quality and look forward to receiving exciting submissions from both academic and industrial contexts.

To close, please allow me to express my gratitude to the following people and institutions: Hermann Engesser who supported and accompanied IFE and CSRD over many years, Sabine Kathke who initiated the transformation from CSRD to SICS, Martin Börger who has organized and finally completed CSRD's metamorphosis into SICS, the SpringerVerlag itself, all the members of the editorial board, the authors of the published articles, and, of course, our readers for their continuing support in reading and enjoying this journal.
Sabine Glesner

sabine.glesner@tu-berlin.de

1 Technische Universität Berlin, Berlin, Germany 